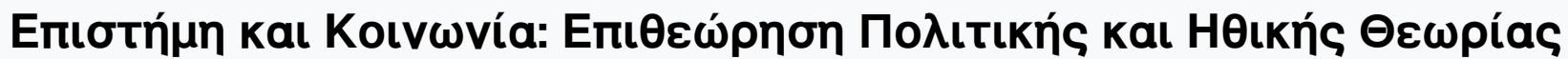

Tó 16 (2006)

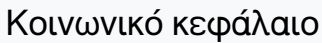

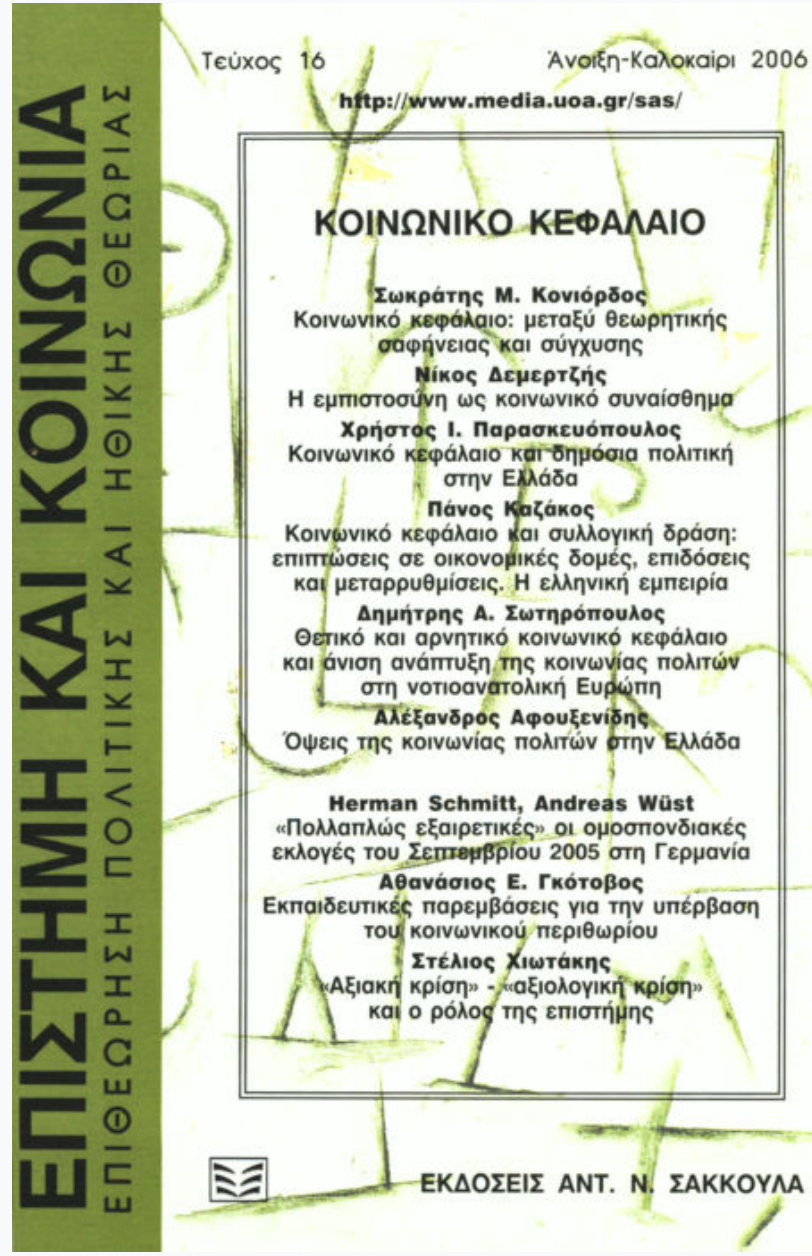

\section{Norberto Bobbio, A political life}

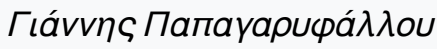

doi: $\underline{10.12681 / \text { sas. } 897}$

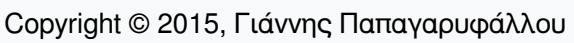

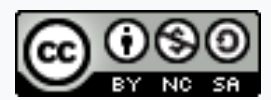

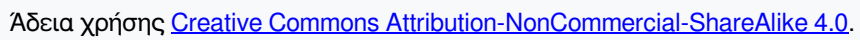

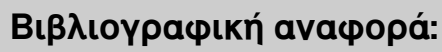

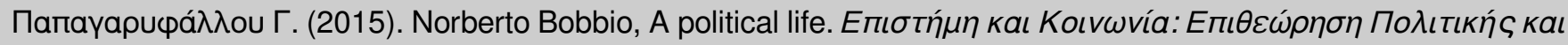

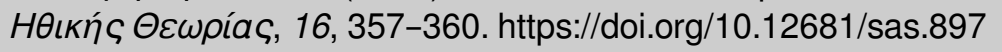




\section{BIB $\Lambda$ IOПAPOY}

\section{Norberto Bobbio, A Political Life, edited by Alberto Papuzzi, Cambridge:

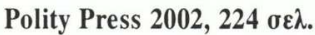

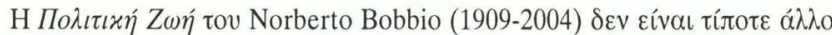

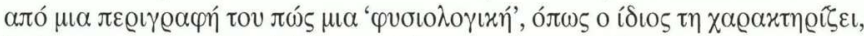

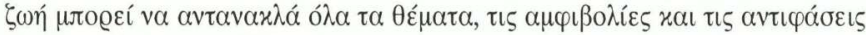

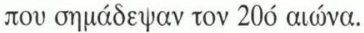

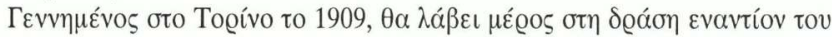

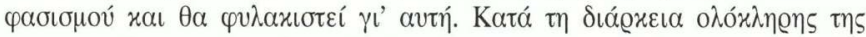

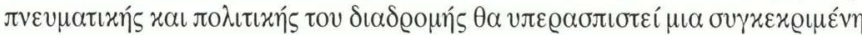

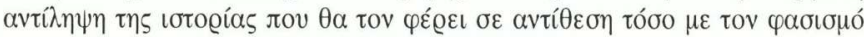

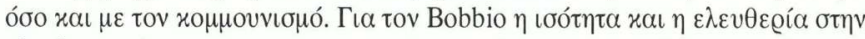

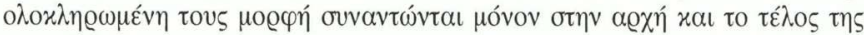

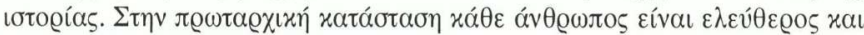

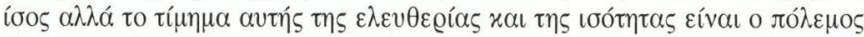

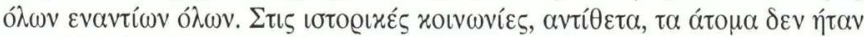

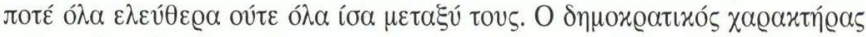

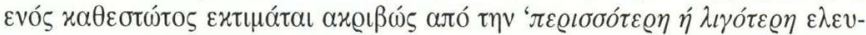

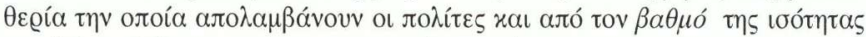

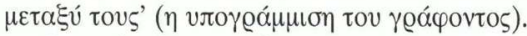

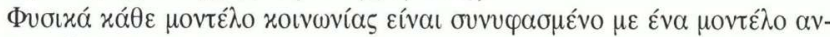

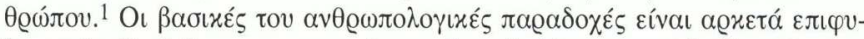

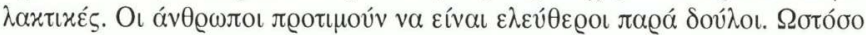

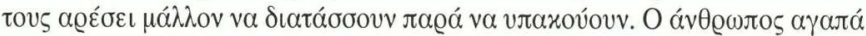

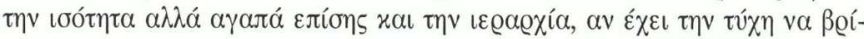

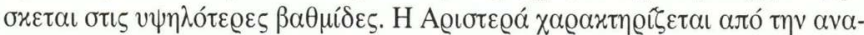

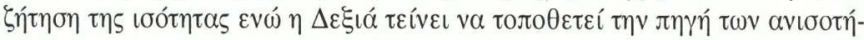

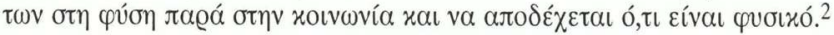

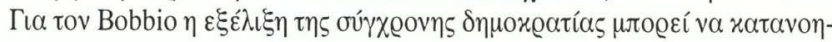




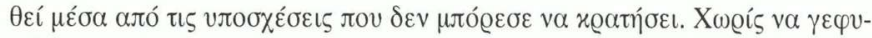

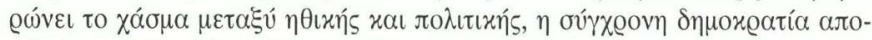

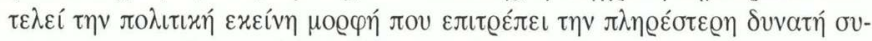

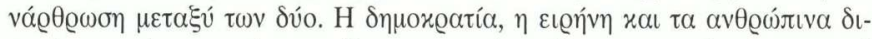

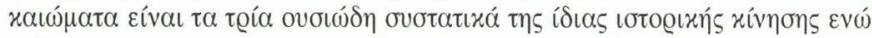

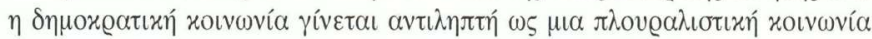

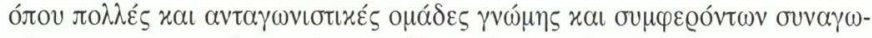

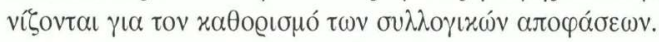

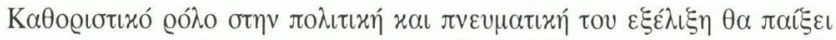

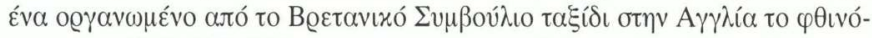

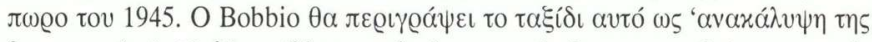

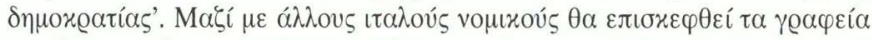

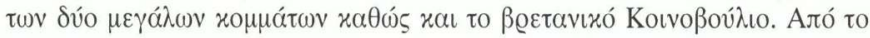

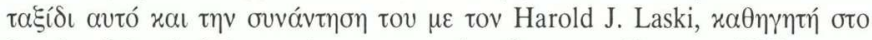

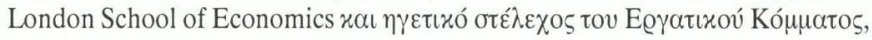

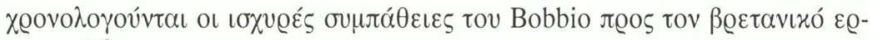

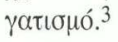

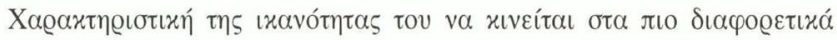

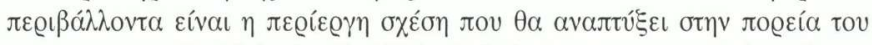

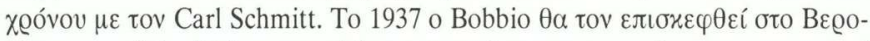

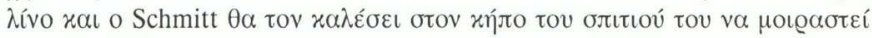

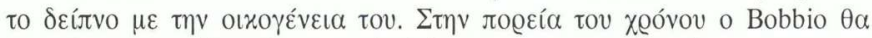

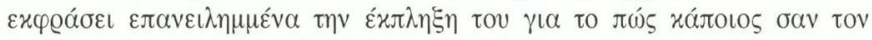

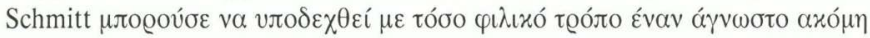

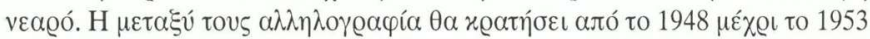

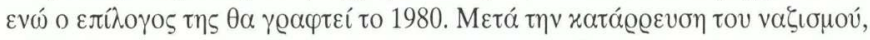

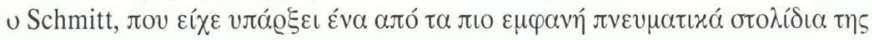

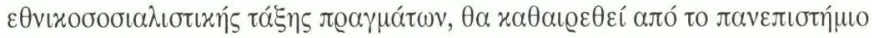

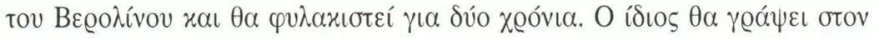

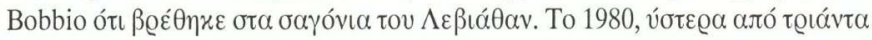

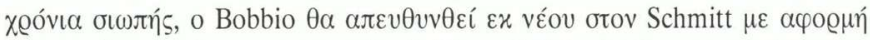

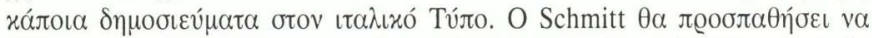

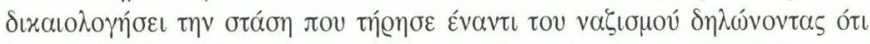

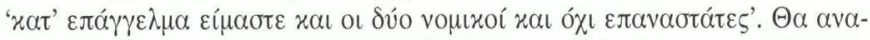

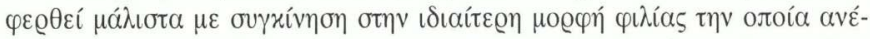

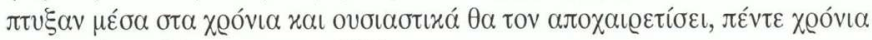

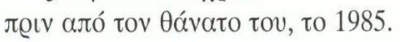




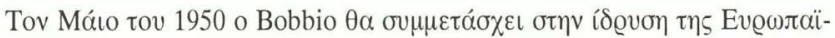

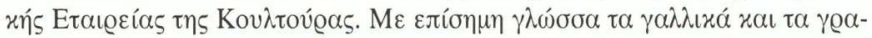

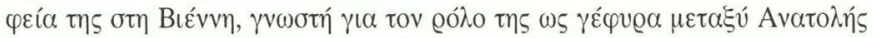

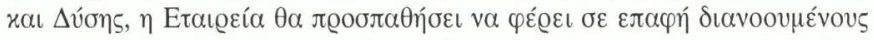

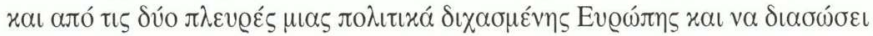

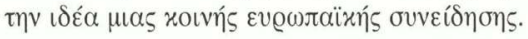

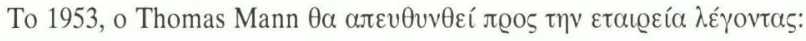

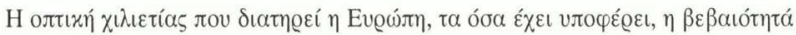

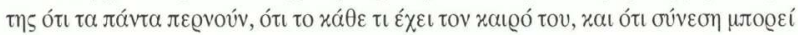

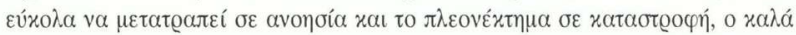

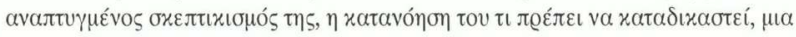

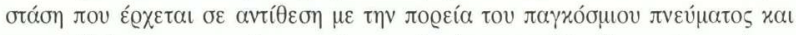

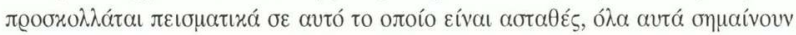

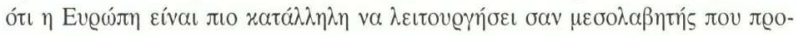

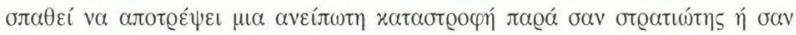

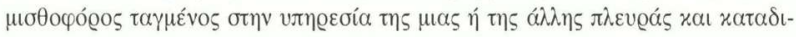

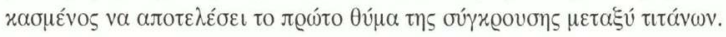

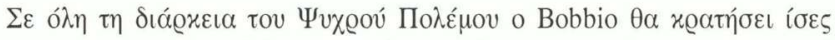

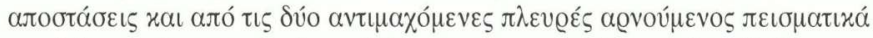
$v \alpha \varepsilon \xi ı \alpha$ เ

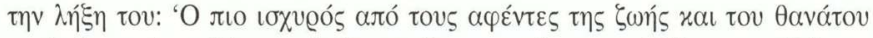

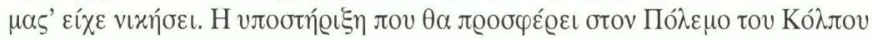

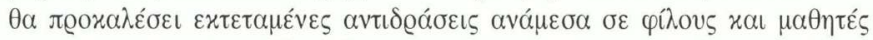

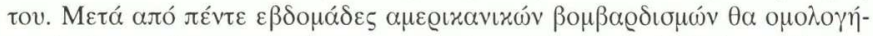

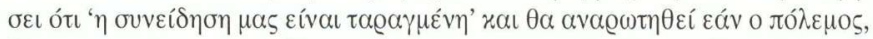

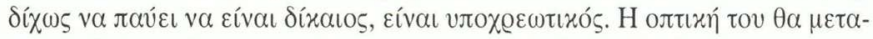

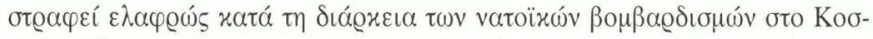

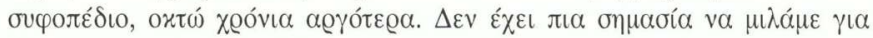

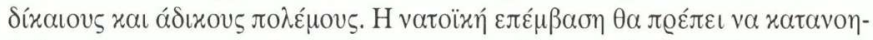

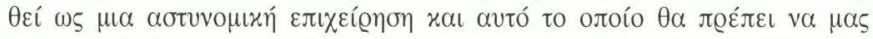

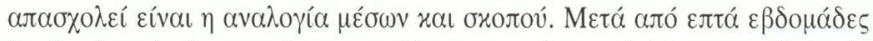

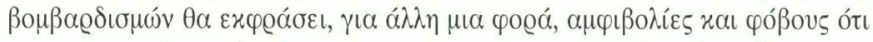

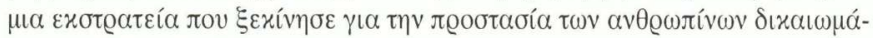

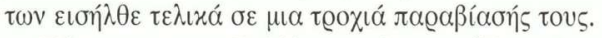

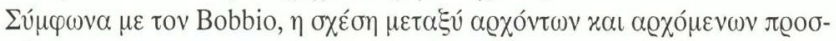

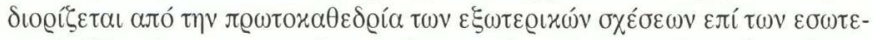

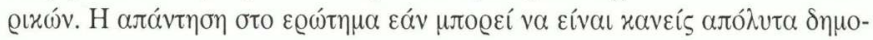




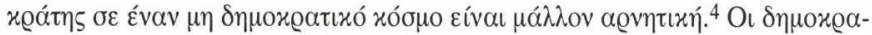

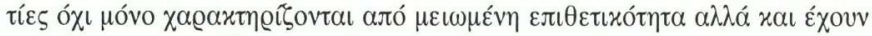

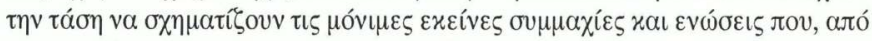

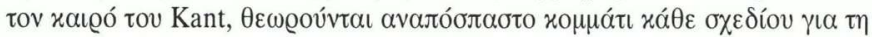

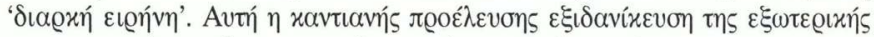

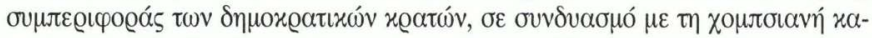

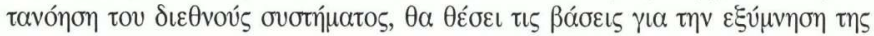

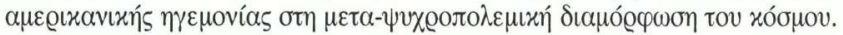

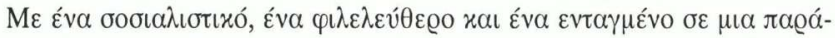

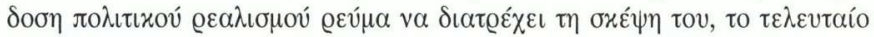

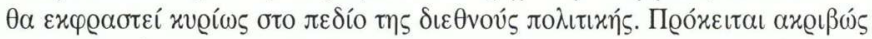

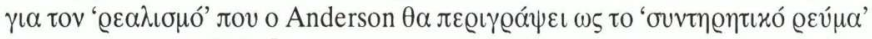

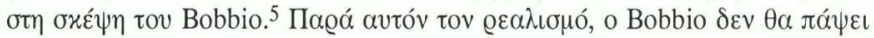

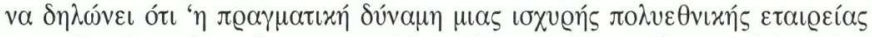

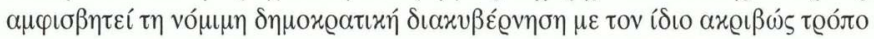

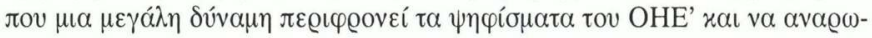

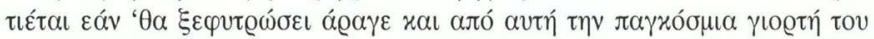

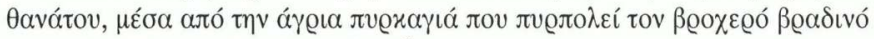

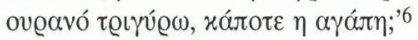

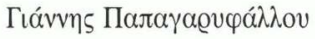

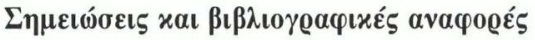

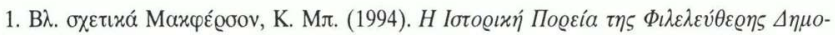

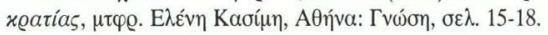

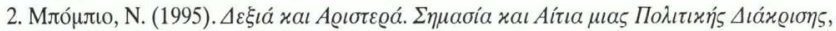

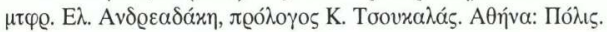

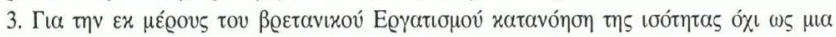

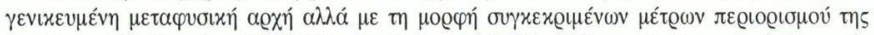

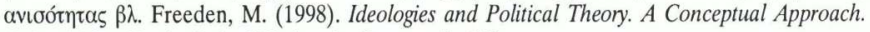
Oxford, New York: Oxford University Press, $\sigma \varepsilon \lambda .465$.

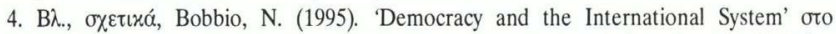

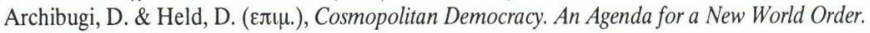
Cambridge: Polity.

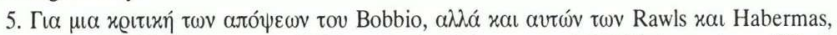
$\beta \lambda$. Anderson, P. (2005). 'Arms and Rights. Rawls, Habermas and Bobbio in an Age of War', New Left Review, 31: 5-40.

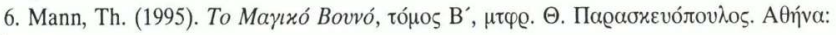

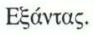

